\title{
COST-EFFECTIVENESS ANALYSIS OF CEFTAZIDIME-LEVOFLOXACIN AND CEFOTAXIME-ERYTHROMYCIN AS EMPIRICAL ANTIBIOTIC COMBINATIONS IN RESPIRATORY INFECTION-INDUCED SEPSIS
}

\author{
DIKA P DESTIANI ${ }^{1 *}$, TIANA MILANDA ${ }^{1}$, SUSILAWATI SUSILAWATI ${ }^{2}$, AULIYA A SUWANTIKA ${ }^{1,3}$, IVAN S PRADIPTA ${ }^{1}$, \\ ELI HALIMAH ${ }^{1}$, AJENG DIANTINI ${ }^{1}$, SRI A SUMIWI ${ }^{1}$, AHMAD MUHTADI ${ }^{1}$, ANAS SUBARNAS ${ }^{1}$, KERI LESTARI $^{1}$, \\ RIZKY ABDULAH ${ }^{1}$
}

${ }^{1}$ Department of Pharmacology and Clinical Pharmacy, Faculty of Pharmacy, Universitas Padjadjaran, Indonesia. ${ }^{2}$ Department of Pharmacy, Hasan Sadikin Hospital, Bandung, Indonesia. ${ }^{3}$ Department of Pharmacy, University of Groningen, Groningen, Netherlands. Email: dika.pramita@unpad.ac.id

Received: 24 December 2016, Revised and Accepted: 24 January 2017

ABSTRACT

Objective: Pharmacoeconomics has become an important consideration in the selection of therapies, including in patients with sepsis caused by respiratory infection. The aim of this study was to determine the most cost-effective antibiotic combination for respiratory infection-induced sepsis at a public hospital in Bandung, Indonesia.

Methods: This retrospective observational study was conducted at one of the public hospitals in Bandung. Two interventions were analyzed: ( $\mathrm{I}_{1}$ ) Ceftazidime-levofloxacin and $\left(\mathrm{I}_{2}\right)$ cefotaxime-erythromycin; and compared to the major treatment ( $\mathrm{I}_{0}$, the use of other antibiotic combinations). Data were collected from the medical records of inpatients with respiratory infection-induced sepsis from 2010 to 2012 . Health-care perspective was applied by considering only direct medical costs, which were calculated from a variable (drug, administrative, and treatment cost) and fixed cost (hospitalization).

Results: Comparing with $\mathrm{I}_{0}$, net cost per life saved was calculated to be $\$ 3,350\left(\mathrm{I}_{1}\right)$ and $\$ 1,589\left(\mathrm{I}_{2}\right)$. Number of patients survived was considered to be the most significant parameter on affecting the calculation of net cost per life saved.

Conclusion: $\mathrm{I}_{2}$ was more cost effective than $\mathrm{I}_{1}$, compared to $\mathrm{I}_{0}$.

Keywords: Empirical therapy, Cost-effectiveness, Pharmacoeconomics, Sepsis, Antibiotics.

(C) 2017 The Authors. Published by Innovare Academic Sciences Pvt Ltd. This is an open access article under the CC BY license (http://creativecommons. org/licenses/by/4. 0/) DOI: http://dx.doi.org/10.22159/ajpcr.2017.v10s2.19515

\section{INTRODUCTION}

Sepsis is a systemic inflammatory response triggered by a known or highly suspected pathogen. The mortality rate of severe sepsis in the world remains high, at approximately $28 \%$ [1]. The previous studies confirmed that respiratory infection is the major cause of sepsis [2,3]. Sepsis caused by respiratory infection can be treated with a combination of a beta-lactamase or cephalosporin plus a fluoroquinolone or macrolide [4,5]. In Indonesia, the most commonly used antibiotic combinations related to sepsis therapy are ceftazidime-levofloxacin and cefotaxime-erythromycin [5]. Hence, in this study, we analyzed the cost-effectiveness of both antibiotic combinations in patients with respiratory infection-induced sepsis.

\section{METHODS}

This retrospective observational study was conducted at one of the public hospitals in Bandung since the prevalence of sepsis caused by respiratory infection was very high (49\%) [4]. Two interventions were analyzed: $\left(\mathrm{I}_{1}\right)$ Ceftazidime-levofloxacin and $\left(\mathrm{I}_{2}\right)$ cefotaximeerythromycin; and compared to the major treatment $\left(\mathrm{I}_{0}\right.$, the use of other antibiotic combinations), which was most commonly used at this hospital and yet in contrast with the general situation in Indonesia. Data were collected from the medical records of inpatients with respiratory infection-induced sepsis from 2010 to 2012. Health-care perspective was applied by considering only direct medical costs, which were calculated from a variable (drug, administrative, and treatment costs) and fixed cost (hospitalization). This study was approved by the Ethical Committee of Universitas Padjadjaran, Indonesia.
A total of 408 sepsis patients (adult patients [18-59 years] with respiratory infection-induced sepsis in 2010-2012 and treated for at least 3 days with an empirical antibiotic combination) were included in this study, while patient transferred from other hospital or with incomplete medical records were excluded from the study.

\section{COST-EFFECTIVENESS ANALYSIS CALCULATION}

Net cost per life saved was calculated by considering the total direct medical cost per life saved from $\mathrm{I}_{1}$ to $\mathrm{I}_{2}$, compared with $\mathrm{I}_{0}$. Discounting the costs was unnecessary since all costs occurred within 1 year. The currency was converted from the Indonesian Rupiah to the US Dollar using the World Bank purchasing power parity conversion factor [6].

\section{RESULTS}

Despite the total number of eligible patients in this study was 90 patients, there were only 24 patients survived $(7,5$, and 12 patients for $I_{1}, 1_{2}$, and $I_{0}$, respectively). The average direct medical costs in this study were $\$ 3,786$; $\$ 6,427$; and $\$ 3,605$ for $I_{1}, 1_{2}$, and $I_{0}$, respectively. In addition, the average direct medical costs in this study were $\$ 3,786$; $\$ 6,427$; and $\$ 3,605$ for all interventions (Table 1 ).

Comparing with $\mathrm{I}_{0}$, net cost per life saved was calculated to be $\$ 3,350\left(\mathrm{I}_{1}\right)$ and $\$ 1,589\left(I_{2}\right)$. Number of patients survived was considered to be the most significant parameter on affecting the calculation of net cost per life saved (Table 2). 
Table 1: Direct medical costs (total patient=90; death=66; survived=24)

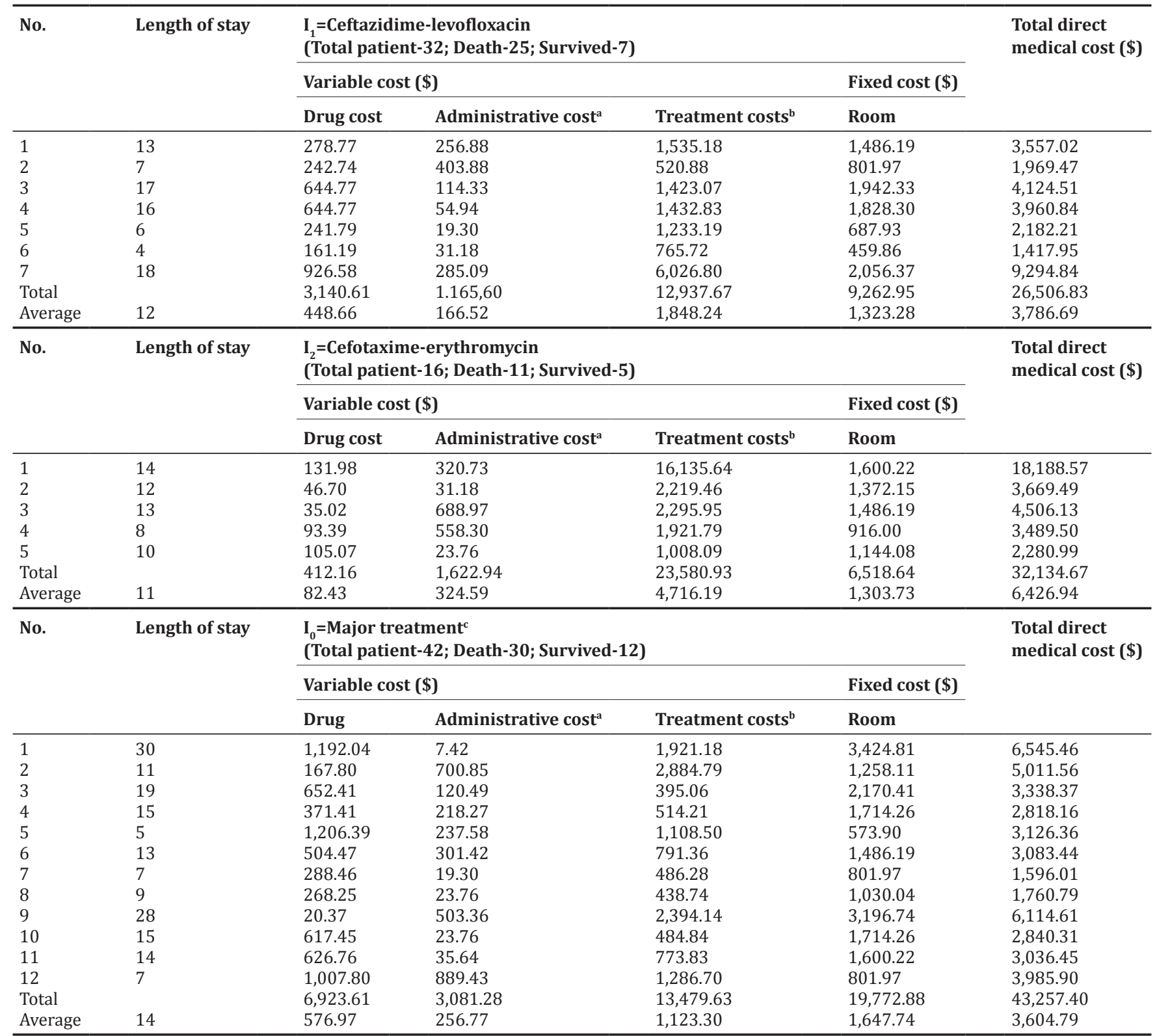

${ }^{a}$ Admininstrative cost - Preparation and administrative costs. ${ }^{b}$ Treatment costs - Monitoring costs and costs of treatment, including adverse events and treatment failure. ${ }^{\mathrm{c}}$ Major treatment - Others antibiotics treatment beside the two antibiotics which are compared in this research: Ampicillin-ciprofloxacin, cefotaxime-azithromycin, cefotaxime-metronidazole, ceftriaxone-metronidazole, ceftazidime-ciprofloxacin, ceftazidime-metronidazole. Intervention $0: \mathrm{I}_{0}$, Intervention $1: \mathrm{I}_{1}$, Intervention $2: \mathrm{I}_{2}$

Table 2: Sensitivity analyses

\begin{tabular}{lll}
\hline Scenarios & \multicolumn{2}{l}{$\begin{array}{l}\text { Net cost per life } \\
\text { saved (\$) }\end{array}$} \\
\cline { 2 - 3 } & $\mathbf{I}_{\mathbf{1}}$ & $\mathbf{I}_{\mathbf{2}}$ \\
\hline Base-case $^{\mathrm{a}}$ & 3,350 & 1,589 \\
Drug cost $(25 \% \uparrow)$ & 3,193 & 1,574 \\
Drug cost $(25 \% \downarrow)$ & 3,507 & 1,604 \\
Administrative cost $(25 \% \uparrow)$ & 3,292 & 1,531 \\
Administrative cost $(25 \% \downarrow)$ & 3,408 & 1,647 \\
Treatment cost $(25 \% \uparrow)$ & 2,703 & 747 \\
Treatment cost $(25 \% \downarrow)$ & 3,997 & 2,431 \\
Fixed cost $(25 \% \uparrow)$ & 2,887 & 1,356 \\
Fixed cost $(25 \% \downarrow)$ & 3,813 & 1,822 \\
Number of patients survived $(25 \% \uparrow)$ & 5,154 & 1,934 \\
Number of patients survived $(25 \% \downarrow)$ & 2,482 & 1,348 \\
\hline
\end{tabular}

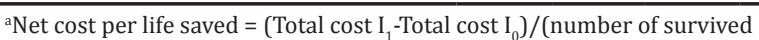
patients $I_{1}$-Number of survived patients $I_{0}$ ). Intervention 0: $I_{0^{\prime}}$ Intervention $1: I_{1^{\prime}}$ Intervention $2: \mathrm{I}_{2}$

\section{DISCUSSION}

Although the drug costs for $\mathrm{I}_{2}(\$ 82.43)$ was lower than $\mathrm{I}_{1}(\$ 448.66)$, the average direct medical cost for $I_{2}(\$ 6,426.94)$ was higher than $I_{1}$ $(\$ 3,786.69)$. This cost difference was due to the extra cost caused by the adverse effects of cefotaxime-erythromycin. This combination causes thrombocytopenia, possibly requiring thrombocyte transfusion, which costs approximately $\$ 890.91 /$ unit. One of the physiological changes in sepsis patients is a decreased thrombocyte level due to thrombocytopenia [7], and the cefotaxime-erythromycin combination may worsen this condition [8]. If the decreased thrombocyte level is $<100,000 / \mathrm{mm}^{3}$, thrombocyte transfusion will be needed to avoid spontaneous bleeding [5,6]. In this study, six patients using cefotaximeerythromycin were diagnosed with thrombocytopenia, of whom one was given a thrombocyte transfusion due to a thrombocyte level of $<50,000 / \mathrm{mm}^{3}[9]$.

Cost per life saved was calculated to be $\$ 3,350$ and $\$ 1,589$ for $I_{1}$ and $I_{2}$, compared to $I_{0}$. This could be interpreted that the combination of 
cefotaxime-erythromycin was more cost effective than ceftazidimelevofloxacin. Thus, also considering the pattern of microbial resistance, the cefotaxime-erythromycin combination could be the better choice of empirical antibiotics in patients with sepsis caused by respiratory infections, as the combination may increase the number of lives saved. Regarding the sensitivity analyses, number of patients survived was the most significant parameter on affecting the calculation of net cost per life saved, compared to other parameters (e.g., variable and fixed costs).

\section{Limitations}

Despite the fact that this study is the first economic evaluation study on sepsis treatment in Indonesia, it obviously has several limitations. First, our study was an observational study, and we did not randomized patients into groups. Yet, according to a previous study [10], this approach also has an advantage since it can better reflect clinical practice. Second, we obtained medical costs from a public hospital in Indonesia which might be cheaper than others. Thus, if sepsis patients were treated in a private hospital, the cost-effective analysis might yield different results. Based on those limitations, further economic evaluation studies are still required in the future.

\section{CONCLUSION}

The use of cefotaxime-erythromycin was more cost effective than ceftazidime-levofloxacin, compared to the use of major treatment.

\section{ACKNOWLEDGMENT}

Authors thank Okky S. Purwanti and Cherry Rahayu for the data collection in this study.

\section{REFERENCES}

1. Khan ZU, Salzman GA. Management of sepsis: The surviving sepsis guidelines for early therapy. Hosp Physician 2007;43:21-30.

2. Angus DC, Linde-Zwirble WT, Lidicker J, Clermont G, Carcillo J, Pinsky MR. Epidemiology of severe sepsis in the united states: Analysis of incidence, outcome, and associated cost of care. Crit Care Med 2001;29:1303-10

3. Danai PA, Moss M, Mannino DM, Martin GS. The epidemiology of sepsis in patients with malignancy. Chest 2006;129:1432-40.

4. Sodik DC. The Pattern of Antibiotic Use and Bacterial Infection of Sepsis Inpatient in Hasan Sadikin Hospital, Indonesia. B. Pharm. Thesis, Faculty of Pharmacy, Universitas Padjadjaran, Bandung, Indonesia; 2012.

5. Department of Internal Medicine Hasan Sadikin Hospital. Standard for Medical Services. Bandung: Faculty of Medicine Universitas Padjadjaran/Hasan Sadikin Hospital; 2008.

6. The World Bank. PPP Conversion Factor, GDP (LCU Per International \$). Available from: http://www.data.worldbank.org/ indicator/PA.NUS.PPP?page=2. [Last cited on 2013 Dec 23].

7. Pea F, Viale P, Furlanut M. Antimicrobial therapy in critically ill patient: A review of pathophysiological conditions responsible for altered disposition and pharmacokinetic variability. Clin Pharmacokinet 2005;44:1009-34.

8. Price SA, Lorraine MW. Pathophysiology: Clinical Concepts and Disease. $6^{\text {th }}$ ed. St. Louis: Mosby; 2002.

9. Segal HC, Briggs C, Kunka S, Casbard A, Harrison P, Machin SJ, et al. Accuracy of platelet counting haematology analysers in severe thrombocytopenia and potential impact on platelet transfusion. $\mathrm{Br} \mathrm{J}$ Haematol 2005;128:520-5.

10. Suarez D, Haro JM, Novick D, Ochoa S. Marginal structural models might overcome confounding when analyzing multiple treatment effects in observational studies. J Clin Epidemiol 2008;61:525-30. 